\title{
Primer sklerozan kolanjiti taklit eden otoimmün kolanjiyopati: Vaka sunumu
}

\author{
Autoimmune cholangiopathy mimicking primary sclerosan cholangitis: A case report
}

\author{
Muhammet Yener AKPINAR, Bülent ÖDEMiş, Sabite KAÇAR, Hale GÖKCAN, Ufuk Barış KUZU, \\ Ertuğrul KAYAÇETIN
}

Türkiye Yüksek İhtisas Eğitim ve Araştırma Hastanesi, Gastroenteroloji Kliniği, Ankara

\begin{abstract}
Otoimmün kolanjiyopati veya immünglobulin G4 ilişkili sklerozan kolanjit immün sistem ilişkili bir kolanjit tipidir. Otoimmün pankreatit sıkıkla bu duruma eşlik eder; bununla beraber hastaların çok az bir yüzdesinde otoimmün kolanjiyopati tek başına da görülebilir. 69 yaşında kadın hasta kliniğimize halsizlik, kaşıntı ve sarılıkla başvurdu. Endoskopik retrograd kolanjiopankreatografi de intrahepatik safra yollarında çok sayıda darlık ve dilatasyonlarla beraber ana koledok distalde darlığa rastlandı. Sklerozan kolanjitin diğer nedenlerini ekarte edebilmek için hastadan immünglobulin G4 çalışıldı ve sonuç 1.200 mg/dl olarak geldi. Bu sonuçla otoimmün kolanjiyopati tanısı kondu. Otoimmün kolanjiyopati intrahepatik ve/veya extrahepatik safra yollarında darlik olan hastalarda ayırıcı tanıda mutlaka akılda tutulmalıdır. Süphe edilen hastalarda immünglobulin G4 tarama amaçlı kullanılabilir. Otoimmün kolanjiyopatinin tanı ve tedavisi hastaları ilerleyen zamanda siroz veya gereksiz cerrahiden koruyacaktır.
\end{abstract}

Anahtar kelimeler: Otoimmün kolanjit, primer sklerozan kolanjit

\section{GíRiş}

Otoimmün kolanjiyopati, diğer isimleri immünglobulin (lg) G4 ilişkili kolanjiyopati ve lgG4 ilişkili sklerozan kolanjit (IgG4-SK) olarak bilinen, safra yollarını etkileyen immün sistem ilişkili bir kolanjit tipidir. Bu hastalık histopatolojik olarak safra yollarının lenfoplazmositer hücrelerle infiltrasyonu ve yüksek lgG4 düzeyleri ile karakterizedir (1). Otoimmün pankreatit sıklıkla IgG4-SK ilişkilidir, bununla beraber hastaların az bir kısmında IgG4-SK tek başına da görülebilir (2).

IgG4-SK'de darlıklar safra yollarının farklı kesimlerinde olabilir. Biz burada sarılıkla başvuran, kolanjiyogramda primer sklerozan kolanjit (PSK) benzeri görünüm izlenen ve tanısı IgG4-SK olarak konulan hastamızı sunduk.

\section{OLGU SUNUMU}

Altmış dokuz yaşında kadın hasta hastanemize halsizlik, kaşıntı ve sarılıkla başvurdu. Başvuru esnasında hastanın laboratuvar parametreleri alanin aminotransferaz (ALT):
Autoimmune cholangiopathy or IgG4-related sclerosan cholangitis is an immune- mediated type of cholangitis. Autoimmune pancreatitis is frequently associated with this condition. However, in a minority of patients, autoimmune cholangiopathy exist alone. A 69- year-old female patient was admitted to our hospital with fatigue, pruritus, and jaundice. There were multiple strictures and dilations in the intrahepatic biliary tree with stricture in the distal part of the common bile duct. To exclude other causes of sclerosan cholangitis, lgG4 was studied. The IgG4 titer was $1200 \mathrm{mg} / \mathrm{dl}$; therefore, the diagnosis was autoimmune cholangiopathy. Autoimmune cholangiopathy must be investigated in patients with biliary strictures in either the intrahepatic or extrahepatic bile ducts. IgG4 can be used to screen for autoimmune cholangitis. Diagnosis and treatment of this condition prevents patients from cirrhosis and unnecessary surgery.

Key words: Autoimmune cholangiopathy, primary sclerosan cholangitis

$84 \mathrm{U} / \mathrm{L}$ (normal: <50), aspartat aminotransferaz (AST): $199 \mathrm{U} / \mathrm{L}$ (normal: <50), gama glutamil transpeptidaz (GGT): $862 \mathrm{U} / \mathrm{L}$ (normal: <55), alkalen fosfataz (ALP): 488U/L (normal:<195), total bilirübin: $6,3 \mathrm{mg} / \mathrm{dl}$ (normal: 0,3-1,2) ve direk bilirubin: 3,6 mg/dl (normal:0-0,2) olarak izlendi. Ultrasonografisinde intrahepatik safra yollarında dilatasyon izlenilen hastaya endoskopik retrograd kolanjiopankreatografi (ERCP) planlandı. ERCP esnasında hastanın kolanjiyografisinde intrahepatik safra yollarında multipl darlık ve darlık proksimalinde dilatasyonlar izlendi, beraberinde distal koledokta da darlık vardı (Resim 1). Koledok distalindeki darlıktan dolayı yapılan fırça sitolojisi negatif geldi. Darlık etiyolojisini araştırmak için yapılan endoskopik ultrasonografide (EUS) pankreas parankimi bal peteği görünümde olup pankreas kanalı inceydi. Ayrıca pankreas başında kitle benzeri bir görünüm izlendi. EUS eşliğinde pankreastaki bu görünümden alınan biyopsi de benign geldi. Sklerozan kolanjitin diğer nedenlerini dışlamak için hastadan IgG4 çalışıldı. IgG4 için sonuç 
1.200 mg/dl olarak geldi. Böylece hastaya IgG4-SK tanısı konulmuş oldu. Hastaya ivedi bir şekilde prednizolon 40 $\mathrm{mg} /$ gün ve ursodeoksikolik asit $1.200 \mathrm{mg} /$ gün dozunda başlandı. Tedavi altında hastanın şikayetleri geriledi ve bilirübin, ALP ve GGT değerleri düştü. Tedavinin ikinci ayında IgG4 düzeyi 200 mg/dl olarak ölçüldü. İkinci ERCP'de intrahepatik safra yolundaki darlıklarda ve distal koledoktaki darlıkta anlamlı iyileşme tespit edildi (Resim 2).

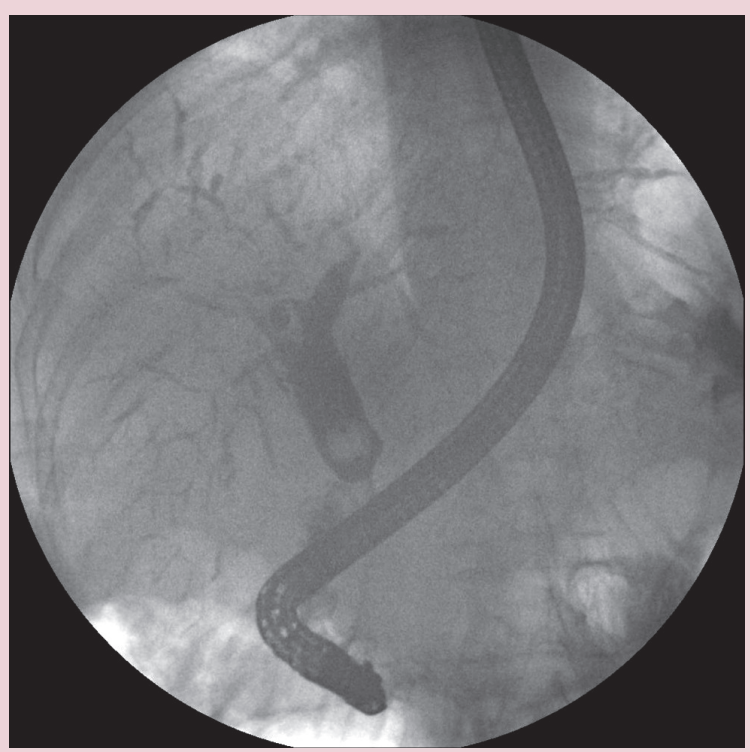

Resim 1. Intrahepatik safra yollarında presitenotik dilatasyonların eşlik ettiği multipl darlıklar. Aynı zamanda koledok distaldeki darlık da görülmekte.

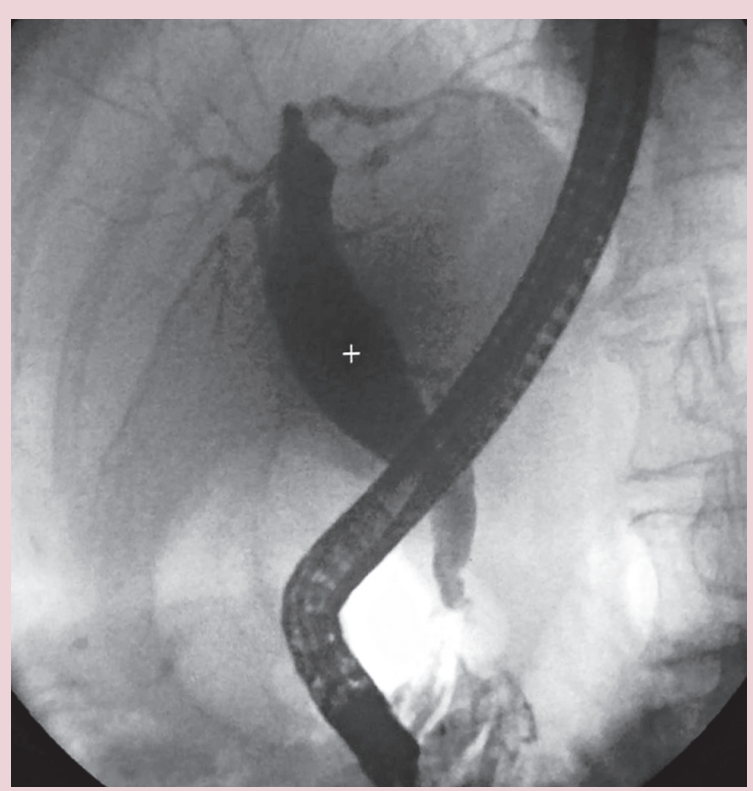

Resim 2. Steroid tedavisi sonrasında intrahepatik safra yollarındaki darlıklar belirgin olarak düzeldi.

\section{TARTIŞMA}

IgG4-SK hastalığının gerçek prevalansı belli değildir. Erkeklerde kadınlara kıyasla 3 kat daha sık izlenen hastaığın ortalama görülme yaşı 69'dur (3). Çoğu hastada IgG4-SK otoimmün pankreatitle beraber görülür. Hastalık klinikte kendisini halsizlik, sarılık, kaşıntı bulguları ile gösterir (4). Laboratuvar bulgusu ALP, GGT ve bilirübinlerde yükselmedir. IgG4 düzeyinin yüksekliği hastalığın en önemli laboratuvar bulgusudur. IgG4'ün 135 mg/dl'den yüksek olması IgG4-SK için \%100 spesifik kabul edilir (5). Histolojik olarak hastaların safra yollarında lenfoplazmositer infiltrasyon ve fibrozis izlenir (6).

Biliyer darlığı olan hastalarda ayırıcı tanıya bir çok benign ve malign hastalıklar girer. Koledok distalindeki darlıklarda malign nedenlerden pankreas kanseri, ampuller tümörler ve distal yerleşimli kolanjiyokarsinom akla gelir. Ortak safra kanalı proksimalinde yerleşik darlıklarda ise Klatskin tümörü ilk akla gelen malignitedir. Darlıklar hem intrahepatik ve hem de ekstrahepatik safra yollarında yaygın olarak görülüyorsa primer sklerozan kolanjit ayırıcı tanıda ilk sıralarda gelir (7).

Geçen yıllarda safra yollarındaki tutulum yeri ve paterni dikkate alınarak dört farklı IgG4-SK tanımlanmıştır (8). Tip-1 koledok distalde izole darlıkla karakterli olup kronik pankreatit, pankreas kanseri ve kolanjiyokarsinomla ayırıcı tanısı yapılmalıdır. Tip-2'de stenotik darlıklar hem intrahepatik hem de ekstrahepatik safra yolunda olup bu nedenle PSK ile ayırıc tanısı yapılmalıdır. Tip-2 kendi içinde iki alt gruba ayrılır. Tip 2a'da intrahepatik safra yollarındaki darlıkların proksimalinde dilatasyon varken Tip $2 b^{\prime}$ de darlık proksimalinde dilatasyon yoktur. Tip-3, hiler bölgede ve koledok distalinde darlıkla karakterlidir. Tip4 'te ise darlık sadece hiler bölgede lokalizedir. Tip-3 ve Tip-4 IgG4-SK'nın, darlıkların yerleşim lokalizasyonundan dolayı mutlaka kolanjiyokarsinomla ayırıcı tanısı yapılmaIıdır. Kolanjiyografik bulgular itibariyle hastamız Tip 2a lgG4-SK kabul edildi.

Steroidler IgG4-SK için temel tedavi ajanıdır. Steroid tedavisine darlıkların yanıtı ekstrahepatik safra yollarına kıyasla intrahepatik safra yollarında daha fazladır. Ne yazık ki steroid tedavisinin kesilmesiyle beraber sıklıkla relaps görülür. IgG4-SK ile otoimmün pankreatitin beraber olması tedavi sonrası relaps riskini artırmaktadır (8).

Sonuç olarak safra yollarının intrahepatik ve/veya ekstrahepatik kısımlarında darlık veya darlıklar tespit edilen hastalarda IgG4-SK mutlaka akılda tutulmalıdır. IgG4 şüphe edilen hastalarda tarama için kullanılabilir. IgG4-SK'in uygun tanısı ve tedavisi hastaları gereksiz cerrahiden ve siroza ilerleyişten korur. 


\section{KAYNAKLAR}

1. Hamano H, Kawa S, Horiuchi A, et al. High serum IgG4 concentrations in patients with sclerosing pancreatitis. $N$ Engl J Med 2001;344:732-8.

2. Nakazawa T, Ikeda Y, Kawaguchi $Y$, et al. Isolated intrapancre atic IgG4-related sclerosing cholangitis. World J Gastroenterol 2015;21:1334-43

3. Navaneethan U, Gutierrez NG, Jegadeesan R, et al. IgG4 levels in bile for distinguishing IgG4-associated cholangiopathy from other biliary disorders: A single blinded pilot study. Clin Endosc 2014;47:555-9.

4. Stone JH, Khosroshahi A, Deshpande V, et al. Recommendations for the nomenclature of IgG4-related disease and its individual organ system manifestations. Arthritis Rheum 2012;64:3061-7.
5. Ohara H, Okazaki K, Tsubouchi H, et al. Clinical diagnostic criteria of IgG4-related sclerosing cholangitis 2012. J Hepatobiliary Pancreat Sci 2012;19:536-42.

6. Tanaka A, Tazuma S, Okazaki K, et al. A nationwide survey for primary sclerosing cholangitis and IgG4-related sclerosing cholangitis in Japan. J Hepatobiliary Pancreat Sci 2014;21:43-50.

7. Zaydfudim VM, Wang AY, de Lange EE, et al. IgG4-associated cholangitis can mimic hilar cholangiocarcinoma. Gut Liver 2015;9:55660.

8. Nakazawa T, Naitoh I, Hayashi K, et al. Diagnosis of IgG4-related sclerosing cholangitis. World J Gastroenterol 2013;19:7661-70. 